\title{
Results of a School-Based Obesity Prevention Program Targeting Early Childhood Students
}

\author{
Tracy Bryars ${ }^{1}$, Michele Mouttapa ${ }^{2}$, Shari McMahan $^{2}$, and Sora Park Tanjasiri ${ }^{2}$ \\ ${ }^{1}$ St. Jude Medical Center/St Joseph Health System \\ ${ }^{2}$ California State University, Fullerton
}

\begin{abstract}
The purpose of this study was to determine whether early childhood students who participated in the Healthy for Life/PE4ME program experienced significant changes in their age-adjusted body mass index (BMI) percentiles, obesity-related behaviors, and identification of healthy foods and physical activities. The school-based program included nutrition education and physical activity components implemented by the teacher and program dietitian. Participants were 356 children and their parents, in17 Southern California schools with a high percentage of ethnically diverse, low income students. Parents completed a survey assessing their children's demographics; family medical history; and obesity-related lifestyle behaviors; at pre-test and post-test. Students completed a picture scale activity to assess their ability to identify healthy versus. unhealthy foods and active vs. less active physical activities. BMI percentiles significantly decreased among children who were overweight or obese at pre-test; they also significantly decreased their junk food consumption (e.g., soda, Cheetos( $)$ ). Obese children at pre-test significantly decreased their consumption of whole milk and increased their consumption of low-fat milk. Normal weight children significantly increased their consumption of milk and their physical activity. These findings provide preliminary evidence that the Healthy for Life/PE4ME program may be effective in reducing the childhood obesity trend in Orange County preschool children.
\end{abstract}

(C) 2012 Californian Journal of Health Promotion. All rights reserved.

Keywords: Childhood Obesity School-Based Prevention/Intervention Program

\section{Introduction}

Approximately 155 million school-aged children worldwide are overweight or obese, and 20 million children younger than five years are overweight (Kraak \& Story, 2010; Stroup, Johnson, Proctor, \& Han, 2009). In the United States, the prevalence of obesity in children ages two through five was $10.4 \%$ (NHANES) $2007-$ 2008 (Ogden, Carroll, Curtin, Lamb, \& Flegal, 2010). Children from ethnic minority, socioeconomically disadvantaged families are at an increased risk of overweight and obesity. For instance, $15 \%$ to $25 \%$ of children are overweight or obese at Head Start preschools, which are U.S.-funded early childhood education programs (Whitaker, Gooze, Hughes, \& Finkelstein, 2009). In 2009, Latino/Hispanic children in Orange County had a $14.8 \%$ rate of overweight among birth to four-year-olds, and $23.2 \%$ among five to eleven-year olds (Children's Services Coordination Committee, 2011). It was estimated that by $2020,21 \%$ of U.S. youths aged 2-19 would be obese, up from $16.9 \%$ based on 1971 to 2008 National Health and Nutrition Examination Surveys trends (Wang, Orleans, \& Gortmarker, 2012).

Multiple factors including the increased consumption of fast food, low-nutrient-density snack foods, and sweetened beverages, as well as increased screen time (which includes television, computer, video games, hand-held play station, and cell phone use), and decreased physical activity have contributed to the rise in childhood overweight and obesity (U.S. Department of Health and Human Services, 2010). Much of obesity among Hispanic/Latino 
Bryars, T., Mouttapa, M., McMahan, S., \& Tanjasiri, S. T. / Californian Journal of Health Promotion 2012, Volume 10, Issue 1, $92-$

children is attributed to food insecurity, low socioeconomic status and acculturation to the U.S. diet and lifestyle (Wilson, Adolph, \& Butt, 2009).

Up to $60 \%$ of children six years or younger spend at least 29 hours per week in childcare or preschools (Iruka \& Carver P, 2006). Hence, a preschool intervention program has the potential of positively impacting obesity trends (Dunn, Thomas, Ward, Pegram, Webber, \& Cullitan, 2006; Eliakim, Nemet, Balakirski, \& Epstein, 2007). Those who are overweight or obese during the preschool years are 26\%-41\% more likely to be obese as adults (Crawford, Mitchell, \& Ikeda, 2002). The literature demonstrates the need to provide nutrition education/resources for preschool teachers and parents (Dunn, et al, 2006; Eliakim, et al., 2007; Whitaker, et al., 2009). Lastly, relatively few obesity prevention/intervention school-based studies have targeted such a young population, who are ethnic minorities and reside in underserved communities.

Childcare providers and preschool teachers may be eager to provide a healthy learning experience for the children, but may lack the necessary education and resources (Dunn et al., 2006). Standards vary depending upon the type of early childhood program. Head Start programs must comply with the Head Start Act of 2007 which supports "children's motor development and overall health and nutrition" (Whitaker et al., 2009, p. 1144). Funds that provide snack and meal coverage come from either the US Department of Agriculture (USDA) by participating in either the National School Lunch and Breakfast Programs or the Child and Adult Care Food Program. Head Start programs that obtained their meal service primarily from the food service program connected with a school district that was identified as having a less healthy menu (Story, 2009; Whitaker et al., 2009).

Several evidence based nutrition and physical activity curricula and training programs have been developed for child care settings. The Color Me Healthy and Sport, Play, Activity, Recreation for Kids (SPARK) are two validated nutrition and physical activity education programs that use the train the trainer model to encourage the diffusion of information among early childhood caregivers and preschool teachers (Dunn et al., 2006; Levin \& Martin, 2002; Prosper, Moczulski, Qureshi, Weiss, \& Bryars, 2009). The Healthy for Life Program utilized both the Color Me Health and the SPARK curriculum which encouraged both nutrition and physical education and behavior during the early childhood school day. Materials were provided in both English and Spanish to meet the needs of the ethnically diverse population of the students and families.

The transtheoretical model and stages of change behavioral approach was used with the Healthy for Life/PE4ME program intervention. This allowed for the consideration of not only the student, but their teachers and families encountered during the school year (Spahn, 2009). The transtheoretical model proposes that people move through a series of stages representing levels of readiness for change (Procopio, 2008). Five distinct stages of change have been identified which include precontemplation, contemplation, preparation, action, and maintenance. In the preschool-based environment, this model may be thought of as talking, thinking, wanting, and doing something about preventing the childhood obesity epidemic. Pre-contemplation is when the participants are not even thinking about making a change or in denial. Contemplation is when the participants have some ambivalence, but are thinking about making a change. Preparation is when the participants are taking active steps to make a change. Action is when the participants are making changes but are not yet stable in their goals. Maintenance is when the participants have accomplished their goals and are working towards maintenance. The stages of change identify points of decision-making which provides the flexibility to move back and forth through the five stages of change (Procopio, 2008). The stages of change was the theoretical foundation utilized for this study.

The purpose of this study was to determine whether early childhood students who participated in the school-based Healthy for 
Life/PE4ME program significantly (1) increased their physical activity, (2) decreased their screen time, (3) improved their nutritional knowledge, and (4) decreased their rates of overweight/obesity over a nine-month period. This program provided teachers with the resources and training to achieve these outcomes and to identify potential barriers that were not currently present in the literature.

\section{Methods}

\section{Study Design and Participants}

A non-experimental, pre-test, post-test design was used for this study. In the 2008-2009 school year, 401 early childhood students were recruited for a convenience sample. The retention rate of the pre to post tests was 356 students. There were 401 consented students who participated in the initial screening physical and parents who completed the student demographic and lifestyle questions survey (11.2-\% attrition rate). Reasons why students did not participate at the yearend (follow-up) assessment varied per the class teacher from sickness, moved, and/or dropped out of class.

Comparisons were made on baseline data between those who did $(n=289)$ and those who did not $(n=67)$ complete the year-end assessment. There were no differences between completers and non-completers on baseline BMI, waist circumference, and 8 out of the 10 lifestyle variables. However we did find that completers had higher baseline rates of eating breakfast $6+$ days per week compared to noncompleters $(71.8 \%$ vs. $56.4 \%$, respectively, $\mathrm{p}<$ $.05)$. We also found that completers had higher rates of eating fruits and vegetables $6+$ days per week compared to non-completers $(40.4 \%$ vs. $20.0 \%$, respectively, $\mathrm{p}<.05)$. These findings suggest that overall, attrition did not vary according to the majority of variables of interest in this study. Nevertheless, our findings may not be fully generalizable to the entire population of interest, which includes those who were lost to follow-up.

The 17 participating schools served low-income, ethnically-diverse Orange County, California populations, and included Head Start preschools, state-funded and Title 1 schools (those with at least $40 \%$ of students receiving free or reduced school meals) with associated preschools. The program manager recruited the Orange County of California preschools by attending Title 1 school district principal meetings, Orange County School Readiness Nurse meetings, Head Start Directors' meetings and individual school district and preschool meetings.

The Healthy for Life/PE4ME program provided the participating schools with equipment, physical education curricula, teacher training, nutrition education curricula, student screening assessments, and parent nutrition presentations. These program components were meant to enhance the already-existing physical activity and nutrition education at the schools. The SPARK (Sports, Play, and Active Recreation for Kids) curriculum and equipment were provided to the teachers (Levin, S. \& Martin, M. B., 2002). SPARK activities focused on active physical activity that promoted gross motor development, creativity and fun, and were relatively easy for teachers to implement in the classroom or on the playground. The SPARK curriculum was designed to involve all children to be highly active, incorporate school readiness skills, and develop more confident and competent movers using the provided equipment such as parachutes, hula hoops, and bean bags. During the school day, the amount of physical activity time for the students provided by the teacher varied from one school to another. Participating early childhood teachers reported an average of 60 to 90 minutes per week of physical activity provided to students. The Color Me Healthy nutrition and physical activity curriculum was designed to be used during circle time (Dunn, et al., 2006). Circle time, also known as group time, involved any time that a group of people are sitting together for an activity involving everyone. The goal of the lessons was to creatively teach children about healthy eating and physical activity, by stimulating the touch, smell, sight, sound, and taste senses of the early childhood student, with the use of color, music, and exploration of the senses. For example, teachers used the Color Me 
Healthy provided 8" x 11 " colorful picture cards of fruits and vegetables during circle time when teaching the colors or seasons of the year to the preschoolers.

Training is provided to all teachers participating in the program. Preschool teachers were trained by a certified Early Childhood trainer for six hours by the Sports, Play \& Active Recreation for Kids (SPARK) program prior to the start of school. At this training, teachers were provided with an overview of how to use the Color Me Healthy curriculum and materials to enhance their ability to teach the children about healthy nutrition choices during circle time 10 to 15 minutes/one to three times per week.

Program dietitians provided two 30 to 45 minute interactive nutrition presentations per year to the parents of the preschool children through $2^{\text {nd }}$ grade students. The nutrition talks were provided during the fall and spring. Nutrition topics discussed included the following: 1. Healthy weight and complications of obesity; 2 . Importance of breakfast, 2010 Dietary Guidelines, Healthy snack ideas; 3. Making healthy choices when dining out/hazards of portion distortion; 4. Decreasing screen time, AAP recommendations; 5. Physical activity 2008 guidelines for children; 6. Rethink your drink and decrease sweetened beverages; and 7. How to read a food label. According to the stages of change behavior model, barriers that often prevent people from changing behavior include lack of knowledge, skills and confidence to engage in behaviors. The nutrition presentations provided the skills and knowledge which empowered the students and parents to make healthier lifestyle choices in any situation. The Healthy for Life/PE4ME program was in its first year (2009) of a four-year grant sponsored by three SJHS hospitals and the St Joseph Health System (Prosper, Moczulski, Qureshi, Weiss, \& Bryars, 2009).

\section{Procedures and Measures.}

The IRB of the first author's affiliation approved study procedures prior to the program implementation. The early childhood students' parents were provided with an information letter, student participation consent form, and a photo consent form at the beginning of the school year prior to the scheduled initial student assessments. Early childhood students provided verbal assent to participate in the program at the time of the initial assessment, and each participating student was assigned a student identification number. Participants and their parents were not compensated for consenting to enroll in the Healthy for Life/PE4ME class. All data was collected in the preschool classrooms, at the beginning and end of the school year during one classroom period. Parents of the early childhood students completed a pre-test and post-test self-report questionnaire containing demographic, family medical history, and 10 lifestyle questions regarding their children at the beginning of the school year and then at the end of the nine-month program. This parent questionnaire was developed by a program steering committee, which was comprised of a board certified pediatrician, a registered dietitian/certified diabetes educator, registered nurses, public health professionals, and academia/research professionals (Prosper, M. H., et at., 2009). The 10 lifestyle questions focused on children's behaviors that have been identified as contributing to the childhood obesity epidemic (Beckman, Hawley, \& Bishop, 2006; California Center for Public Health Advocacy, PolicyLink, \& UCLA Center for Healthy Policy Research, 2008; Covic et al., 2007; Dunn et al., 2006; Eliakim et al., 2007; Freedman \& Alvarez, 2010; Laurson, Eisenmann, Welk, Wickel, Gentile, \& Walsh, 2008; Maher, Carter, \& Johnson, 2008). See Appendix A.

The early childhood students completed a validated picture scale activity (Calfas et al., 1991). This data was collected during a one-onone structured interview format. The program Assessment Team Members (ATM) were trained to use a structured interview guide to ask the students which food is a healthier choice (e.g., Fruit Loops( ${ }^{\circ}$ vs. Cheerios( $)$ ) and which physical activity is a healthier choice between two options (e.g., sitting and rolling the ball vs. running and kicking the ball; Calfas et al., 1991). Students completed a total of 12 picture scale pairs. See Appendix B. The ATMs also obtained the children's anthropometric measurements at 
pre-test and post-test, and included height and weight (to calculate BMI), and waist circumference. The children's height was measured without them wearing shoes using a portable stadiometer. Weight was obtained using a digital calibrated portable scale. The students were weighed without their shoes and without wearing sweat shirts/sweaters/jackets. The waist circumference was obtained using a gulick tape. The measurement was obtained measuring above the child's bare iliac crest (Katzmarzyk, Srinivasan, Chen, Malina, Bouchard \& Berenson, 2004). A board-certified pediatrician completed a screening physical for each student at pre-test. Students identified as obese (BMI $\geq$ $95^{\text {th }}$ percentile), with abnormal cardiac issues, and/or acanthosis nigricans (a physical sign of insulin resistance), were referred for further medical assessment by their primary care physician or a local clinic health care professional. The data obtained was recorded on medical assessment forms that were scanned into St. Joseph Health System's Teleforms program. The TeleForm program was designed to efficiently read hand-print, machine print, optical mark, and signatures from paper forms and documents and validate them without manual intervention or human error. The anthropometric, demographic, lifestyle questionnaire and the picture scale activity data were then entered into an SPSS database for analyses.

\section{Results}

\section{Demographic Characteristics of the Sample.}

Table 1 presents the descriptive statistics that were conducted on the variables of interest. Out of 356 participating early childhood students, 177 of them (49.9\%) were male and 178 of them $(50.1 \%)$ were female. The mean age was 5.69 years $(\mathrm{SD}=.9)$. Three fourths of the early childhood students were between 5 and 6 years of age ( 5 years $n=135$ and 6 years $n=133$ ). Almost three quarters of the participants $(70.5 \%)$ were Latino $(n=251)$ and $49.2 \%$ of the parents $(\mathrm{n}=175)$ indicated that Spanish was their primary language. BMI Percentile/Acanthosis Nigricans
Of the 356 participants, $15.8 \%(\mathrm{n}=56)$ were identified as overweight $\left(\mathrm{BMI}=85^{\text {th }}-94^{\text {th }}\right.$ percentile) and $18.6 \%(\mathrm{n}=66)$ were obese $(\mathrm{BMI}$ $\geq 95^{\text {th }}$ percentile). The BMI percentile mean was $62.1 \quad(\underline{\mathrm{SD}}=29.0)$. Seventeen participating students (4.8\%) were identified as having Acanthosis Nigricans by the program physician during the initial screening physical assessment.

Table 1

Baseline Characteristics of the Sample

\begin{tabular}{|c|c|c|}
\hline & $\mathrm{n}$ & $\%$ \\
\hline \multicolumn{3}{|l|}{ Gender } \\
\hline Male & 177 & 49.9 \\
\hline Female & 178 & 50.1 \\
\hline \multicolumn{3}{|l|}{ Ethnicity } \\
\hline Latino & 251 & 70.5 \\
\hline Non-Latino & 105 & 29.5 \\
\hline \multicolumn{3}{|l|}{ Language } \\
\hline Spanish & 175 & 49.2 \\
\hline English & 168 & 47.2 \\
\hline \multicolumn{3}{|l|}{ Age in Years } \\
\hline 3 & 2 & .6 \\
\hline 4 & 14 & 4.7 \\
\hline 5 & 135 & 39.6 \\
\hline 6 & 133 & 39.0 \\
\hline $7+$ & 57 & 16.7 \\
\hline Acanthosis Nigricans & 17 & 4.8 \\
\hline \multicolumn{3}{|l|}{ Body Mass Index } \\
\hline \multicolumn{3}{|l|}{ Percentile } \\
\hline $\begin{array}{l}\text { Children with normal BMI } \\
\text { percentile }^{\text {th }}\end{array}$ & 234 & 65.6 \\
\hline $\begin{array}{l}\text { Children BMI } 85^{\text {th }}-94^{\text {th }} \\
\text { percentile }\end{array}$ & 56 & 158 \\
\hline Children BMI $\geq 95^{\text {th }}$ & & \\
\hline percentile & 66 & 18.6 \\
\hline
\end{tabular}

\section{Anthropometric Changes}

Table 2 displays paired sample $t$-test results for mean age and sex adjusted BMI percentiles for normal weight, overweight, and obese participants separately. At pre-test, the mean BMI percentile for overweight students was 92.7 $(\mathrm{SD}=4.5)$; their $\mathrm{BMI}$ percentile significantly decreased to $89.4(\mathrm{SD}=11.8)$ at post-test $(\mathrm{t}=$ 3.36, $\mathrm{p}=.001)$. The mean BMI percentile for obese participants at pre-test was $96.6(\mathrm{SD}=.8)$; their BMI percentile significantly decreased to 
94.6 at post-test $(t=2.03, p=.05)$. Finally, at pre-test, the mean BMI percentile of normal weight students was $43.4(\mathrm{SD}=19.9)$. Their BMI percentile significantly increased to 50.1 at posttest $(\mathrm{t}=-5.66, \mathrm{p}=.000)$, which is still well within the normal weight range.

Table 2

Changes in Body Mass Index Percentiles

\begin{tabular}{lllll}
\hline & $\underline{\mathrm{M}}$ at Pretest & $\underline{\mathrm{M}}$ at Posttest & $t$-score & $p$-value \\
\hline $\begin{array}{lllll}\text { Dependent Variables } \\
\text { BMI Percentile }\end{array}$ & & & & \\
$\mathrm{BMI}<85^{\text {th }}(\mathrm{n}=169)$ & $43.4(\mathrm{SD}=19.9)$ & $50.1(\mathrm{SD}=24.2)$ & -5.66 & $.000^{*}$ \\
$\mathrm{BMI} 85^{\text {th }}-94^{\text {th }}(\mathrm{n}=56)$ & $92.7(\mathrm{SD}=4.5)$ & $89.4(\mathrm{SD}=11.8)$ & 3.36 & $.001^{*}$ \\
$\mathrm{BMI} \geq 95^{\text {th }}(\mathrm{n}=54)$ & $96.6(\mathrm{SD}=.8)$ & $94.6(\mathrm{SD}=7.3)$ & 2.03 & $.05^{*}$ \\
\hline$* P=$ statistically significant & & & &
\end{tabular}

Table 3

Changes in Lifestyle Variables (Parents' report on their child)

\begin{tabular}{|c|c|c|c|c|c|c|c|c|c|}
\hline & \multicolumn{3}{|c|}{$\mathrm{BMI}<85^{\text {th }}(\mathrm{n}=194)$} & \multicolumn{3}{|c|}{ BMI $85^{\text {th }}-94^{\text {th }}(n=56)$} & \multicolumn{3}{|c|}{$\mathrm{BMI} \geq 95^{\text {th }}(\mathrm{n}=66)$} \\
\hline & $\begin{array}{c}\text { Baseline } \\
\%\end{array}$ & $\begin{array}{l}\text { Follow- } \\
\text { up\% }\end{array}$ & $\mathrm{z}$ & $\begin{array}{c}\text { Baseline } \\
\%\end{array}$ & $\begin{array}{l}\text { Follow } \\
\text {-up\% }\end{array}$ & $\mathrm{z}$ & $\begin{array}{c}\text { Baseline } \\
\%\end{array}$ & $\begin{array}{c}\text { Follow- } \\
\text { up\% }\end{array}$ & $\mathrm{z}$ \\
\hline $\begin{array}{c}\text { PA 60 } \\
\text { Min/day }\end{array}$ & & & $3.65^{* * *}$ & & & -.65 & & & -.69 \\
\hline 0-2 days/wk & 17.8 & 4.1 & & 10.7 & 2.3 & & 8.2 & 2.2 & \\
\hline 3-5 days/wk & 45.6 & 49.3 & & 47.3 & 59.8 & & 54.1 & 58.7 & \\
\hline $6+$ days/wk & 36.7 & 46.6 & & 42.0 & 37.9 & & 37.7 & 39.1 & \\
\hline $\begin{array}{l}\text { Eats Junk } \\
\text { Food }\end{array}$ & & & -.37 & & & $-1.98 *$ & & & $-2.55 * * *$ \\
\hline 0-2 days/wk & 59.9 & 59.3 & & 52.8 & 62.1 & & 55.0 & 67.4 & \\
\hline 3-5 days/wk & 33.9 & 36.7 & & 37.7 & 34.5 & & 35.0 & 28.3 & \\
\hline $6+$ days/wk & 6.2 & 6.2 & & 9.4 & 3.4 & & 10.0 & 4.3 & \\
\hline $\begin{array}{c}\text { Drink } 2-3 \\
8 \text { oz milk/day }\end{array}$ & & & $-3.12 * *$ & & & -1.30 & & & -1.45 \\
\hline $0-2$ days/wk & 10.7 & 4.7 & & 18.5 & 11.6 & & 9.8 & 4.4 & \\
\hline 3-5 days/wk & 34.8 & 30.0 & & 32.4 & 26.7 & & 42.5 & 24.4 & \\
\hline $6+$ days/wk & 54.5 & 54.5 & & 49.1 & 61.6 & & 47.5 & 71.1 & \\
\hline Milk Type & & & -1.7 & & & -5.7 & & & $-1.97 *$ \\
\hline Whole & 28.7 & 22.4 & & 24.3 & 25.3 & & 23.0 & 19.6 & \\
\hline $2 \%$ Low-fat & 57.3 & 58.5 & & 52.3 & 52.9 & & 57.4 & 54.3 & \\
\hline Non-fat & 1.7 & 3.4 & & 8.4 & 4.6 & & 9.8 & 6.5 & \\
\hline $1 \%$ Low-fat & 8.4 & 13.6 & & 9.3 & 13.8 & & 9.8 & 19.6 & \\
\hline Soymilk & 1.7 & 0 & & 3.7 & 2.3 & & 0 & 0 & \\
\hline None & 2.2 & 2.0 & & 1.9 & 1.1 & & 0 & 0 & \\
\hline
\end{tabular}




\section{Lifestyle Variables}

The Wilcoxon-signed-ranks tests were calculated to assess changes, from paired pretest to post-test, on parent-reported lifestyle variables for normal weight, overweight and obese preschoolers separately as indicated in Table 3. For normal weight children, parent reports of their children's duration of physical activity, which was participating in 60 minutes or more per day, significantly increased from pretest to posttest $(\mathrm{z}=-3.65, \mathrm{p}=.001)$. Findings were not statistically significant among overweight and obese children. The parentreported frequency of junk food (such as

whole milk from pre-test to post-test $(\mathrm{z}=-1.97$, $\mathrm{p}=.05)$; such findings were not present among normal weight and overweight participants. Of the 356 participants who completed the baseline assessment, 289 of them $(81.2 \%)$ also completed a year-end assessment.

Table 4 displays mean scores for the 12 picture scale activities. Possible scores on the healthy cookies, candy, soda, Cheetos $@$, Doritos $@$, etc.) consumption significantly decreased among overweight children $(\mathrm{z}=-1.98, \mathrm{p}=.05)$ and obese children $(\mathrm{z}=-2.55, \mathrm{p}=.001)$, but not for normal weight children. Parents' reports of their preschoolers' milk consumption also changed. Specifically, normal weight children increased their frequency of drinking 2-3 $8 \mathrm{oz}$ cups of milk in a day from pre-test to post-test $(\mathrm{z}=-3.12, \mathrm{p}=$ $.01)$. There were no significant findings for milk consumption frequency among overweight and obese preschoolers. However, obese early childhood students drank significantly less

food items ranged from $0-6$, as was the case for physical activity items. Paired samples t-test results indicated that scores on the physical activity items significantly increased from pretest to post-test among normal weight children, $(\mathrm{t}=-2.2, \mathrm{p}=.03)$, but this was not the case for overweight or obese children. There were no significant findings for the remaining lifestyle variables: screen time, consumption of fast food, breakfast, fruits, vegetables and healthy snacks.

Table 4

Children's Knowledge of and Preference for Healthy Food and Physical Activity

\begin{tabular}{|c|c|c|c|c|c|c|c|c|c|c|c|c|c|c|c|}
\hline & \multicolumn{5}{|c|}{$\mathrm{BMI}<85^{\text {th }}(\mathrm{n}=194)$} & \multicolumn{5}{|c|}{ BMI $85^{\text {th }}-94^{\text {th }}(\mathrm{n}=56)$} & \multicolumn{5}{|c|}{$\mathrm{BMI} \geq 95^{\text {th }}(\mathrm{n}=66)$} \\
\hline & \multicolumn{2}{|c|}{ Baseline } & \multicolumn{3}{|c|}{ Follow-up } & \multicolumn{2}{|c|}{ Baseline } & \multicolumn{3}{|c|}{ Follow-up } & \multicolumn{2}{|c|}{ Baseline } & \multicolumn{3}{|c|}{ Follow-up } \\
\hline & M & SD & $\mathrm{M}$ & SD & $\mathrm{z}$ & $\mathrm{M}$ & SD & M & SD & $\mathrm{z}$ & $\mathrm{M}$ & SD & $\mathrm{M}$ & $\mathrm{SD}$ & $\mathrm{z}$ \\
\hline $\begin{array}{l}\text { Healthy } \\
\text { Food }\end{array}$ & & & & & & & & & & & & & & & \\
\hline $\begin{array}{l}\text { Scores } \\
\text { PA }\end{array}$ & 3.2 & 1.57 & 3.42 & 1.36 & -1.7 & 3.1 & 1.62 & 3.3 & 1.37 & -1.43 & 2.9 & 1.66 & 3.2 & 1.39 & -1.03 \\
\hline Scores & 3.4 & 1.62 & 3.74 & 1.27 & $-2.2 *$ & 3.3 & 1.55 & 3.4 & 1.29 & -0.91 & 3.3 & 1.35 & 3.6 & 1.31 & -1.05 \\
\hline
\end{tabular}

\section{Discussion}

The purpose of this study was to determine whether early childhood students who participated in the nine-month Healthy for Life/PE4ME program experienced significant changes in their BMI percentile, parental reports of obesity-related lifestyle behaviors, and children's self-reported knowledge of healthy food and physical activity choices. We found that: (1) normal weight children increased their consumption of milk and time spent engaging in physical activity, as well as knowledge about physical activity choices; (2) overweight and obese children decreased their junk food consumption; and (3) obese children significantly decreased their consumption of whole milk and increased their consumption of lower fat milk. Relatively few obesity prevention/intervention school-based studies have targeted a young population of ethnic minorities residing in underserved communities. 
The study findings that children increased their knowledge and preference of healthy foods and physical activity suggests that the early childhood school environment provides an excellent opportunity to encourage healthy nutrition and physical activity learning experiences and behaviors (Dunn et al., 2006; Eliakim et al., 2007; Maher et al., 2008; Whitaker et al., 2009). Therefore, it is possible that the establishment of federal and state regulations for age-appropriate nutrition education, and nutritious meals and snacks for children in the early childhood school/daycare environment would provide them with a foundation for developing healthy nutrition and physical activity knowledge and behaviors. Establishing healthy lifestyle behaviors before an operational level of cognitive development (7 to 8 year olds) is necessary before children can fully understand the relationships between their food choices and their health consequences (Calfas et al., 1991). Hence, more research is needed to justify setting physical activity and nutrition federal standards in the early childhood school/child care setting (U.S. Department of Health and Human Services, 2010).

Parents of normal weight children reported that their children increased their physical activity (combined at home and at school) during the 9month study period. The increased amount of physical activity reported by the parents may have occurred as a result of teacher SPARK training, SPARK and Color Me Healthy curricula, and SPARK equipment resources provided to the teachers. The nutrition, physical activity and health information Tip of the Week provided to the school teachers and administrators to distribute to the student's parents may have also increased the parents' knowledge of healthy lifestyles and improved their behaviors. The Tip of the Week was provided in both English and Spanish to accommodate the Spanish primary speaking parents and empower them to be healthy role models. Unfortunately, parents of overweight/obese children did not report increased physical activity at post-test. This observation points to the need to better understand how the early childhood school/child care environment may promote increased physical activity with children at risk for overweight-obesity (Maher, et al., 2008; Kraak \& Story, 2010). Currently, specific physical activity standards for the early childhood students and child care settings are not clearly defined or consistently followed (San Diego State University, 2007). It has been suggested that federal and state-level standards should be developed and enforced for this age group. (Whitaker et al., 2009).

Parents of both overweight and obese children reported a decrease in the consumption of junk food. The decreased consumption of junk food observed in this study may be a result of the parent nutrition presentations provided by the program's registered dietitians and the Tip of the Week sent to the teachers and shared with the students' parents. Healthy food choices, label reading, portion control and increased physical activity education was emphasized during the nutrition talks and in the Tip of the Week fact sheets. The nutrition presentations and written handouts were provided in both English and Spanish to accommodate the more than seventy percent of the preschool children who were Latino and the nearly fifty percent of the families' primary language spoken being Spanish. The findings from the Viva la Familia Study conducted by Wilson et al. (2009) with low SES Latino families are consistent with the results from this study. Consequently, as discussed earlier, teaching a young child healthy nutrition choices and encouraging physical activity has become the responsibility of both the family and the child's caregivers (Freedom \& Alvararez, 2010). The parent-reported decreased junk food consumption among early childhood students may also be linked to their lowered BMI percentile from pre-test to posttest.

The frequency of parent-reported milk consumption increased for normal-weight children. The program encouraged parents and students to participate in a local campaign, "Rethink Your Drink," to achieve the 2010 Dietary Guidelines of drinking 2-3 8 oz servings of milk per day for this age group, and drinking water instead of sweetened beverages (Crawford, Woodward-Lopez, Ritchie, \& Webb, 
2008; U.S. Department of Agriculture \& U.S. Department of Health and Human Services, 2010). Parents of the early childhood students were encouraged to sign a "Rethink Your Drink" commitment form at the beginning of the school year for themselves and their children. Also, parents of obese early childhood students reported a decreased consumption of whole milk and an increased consumption of $1 \%$ low fat milk. Consuming the 2010 Dietary Guidelines suggested amount of lower fat milk may have contributed to improvements in obese children's BMI percentiles. To ensure that parents understand the American Academy of Pediatrics and the Academy of Nutrition and Dietetics guidelines of transitioning children from whole milk to $1 \%$ low-fat milk at age 2 , it is suggested that pediatricians educate parents at the 2-year well child visit (Gee, Rogers, Liu, \& McGarth, 2008).

\section{Limitations}

Limitations of this study included information bias among the parent participants and teachers' attitudes toward the program. Preschool parents may not have accurately reported their child's screen time, dietary behaviors and physical activity, either due to pressures of social desirability or misperceptions of actual behavior. Sampling bias may also have been a limitation as a result of the study sample not being randomly selected. Furthermore, the dose of the intervention may have varied among classrooms, depending upon the extent to which the preschool teacher was supportive of the program and was motivated to utilize the program-related resources and training provided to them. It was therefore not possible to assess the relationship of the increased dose of physical activity with the study results. Lastly, there was a $18.8 \%$ $(n=67)$ student attrition rate from the baseline to the follow-up assessment. Lastly, our findings may not be fully generalizable to the entire population of interest, which includes those who were lost to follow-up. As mentioned earlier, those who comprised the analytic sample for our study had higher rates of eating breakfast, fruits, and vegetables compared to those who were lost to follow-up.

\section{Conclusion}

The study results demonstrate that more research is needed to justify setting and enforcing physical activity and nutrition standards in early childhood school/child care settings. The Healthy for Life physicians, dietitians and teachers reported anecdotally that challenges still exist among families who are overworked, lack financial resources and lack access to healthy foods and safe play areas. Physicians are respected, and parents are receptive to discussions about the importance of healthy weight, nutrition choices, physical activity, and reduced screen time guidelines for their children (Maher et al., 2008; U.S. Preventive Services Task Force, 2010). Therefore it is suggested that physicians routinely obtain and discuss body mass index percentile status with parents at their child's well check-ups. More research is needed to identify the benefit of linking physicians with overweight/obese students from the school environment. According to the California Obesity Prevention Plan, (2010) health care insurers and providers will increasingly adopt practices and polices that promote obesity prevention and early treatment by December 2015.

The Healthy for Life/PE4ME program has expanded to 57 Orange County preschools serving 1,169 preschool children over the past three years. We have observed that many of the teachers involved with the program have influenced school administrators to create a healthier school environment for students, teachers and staff. With the approval of the principal, one of our preschool school teachers worked with the food service department to establish only healthy snack offerings, such as apples and string cheese, during the morning nutrition break. Through teacher observations and annual on-line program evaluations, the quality and effectiveness of the teacher training, program implementation, student assessments, and parent attendance at the nutrition presentations have improved over the past three years. We have also learned that a key factor in the overall success of the Healthy for Life/PE4ME program at our preschools is 
Bryars, T., Mouttapa, M., McMahan, S., \& Tanjasiri, S. T. / Californian Journal of Health Promotion 2012, Volume 10, Issue 1, $92-$

selecting determined and motivated program teachers and gaining the support of school administrators. Creating healthy early childhood school/child care settings that focus on modeling and teaching good nutrition and physical activity will promote children's optimal growth, development, and healthy weight.

\section{References}

Beckman, H., Hawley, S., \& Bishop, T. (2006). Application of theory-based health behavior change techniques to the prevention of obesity in children. Journal of Pediatric Nursing. 21(4), 266-275. doi:DOI: 10.1016/j.pedn.2006.02.012

Calfas, K. J., Sallis, J. F., \& Nader, P. R. (2006). The development of scales to measure knowledge and preference of diet and physical activity behavior in 4- to 8-year-old children. Developmental and Behavioral Pediatrics. 12(3), 185-190.

California Center for Public Health Advocacy, PolicyLink, \& UCLA Center for Healthy Policy Research. (2008). Designed for disease the link between local food environments and obesity and diabetes. Policy Brief Regents of the University of California.

California Department of Public Health, Califorina Obesity Prevention Program.(2010). California obesity prevention plan: a vision for tomorrow, strategic actions for today, Sacramento (CA). Sacramento, CA.

Children's Services Coordination Committee. (2009). The 15th annual report on the conditions of children in Orange County, 2009. (15). Fullerton, CA: California State University Fullerton.

Covic, T., Roufeil, L., \& Dziurawiec, S. (2007). Community beliefs about childhood obesity: Its causes, consequences and potential solutions. Journal of Public Health. 29(2), 123-131.

Crawford, P. B., Mitchell, R., \& Ikeda, J. (2002). Childhood overweight a fact sheet for professionals. Cooperative Extension, Department of Nutritional Sciences, University of California Berkeley.

Crawford, P. B., Woodward-Lopez, G., Ritchie, L., \& Webb, K. (2008). How discretionary can we be with sweetened beverages for children? Journal of the American Dietetic Association. 108(9), 1440-1441.

Dunn, C., Thomas, C., Ward, D., Pegram, L., Webber, K., \& Cullitan, C. (2006). Design and implementation of a nutrition and physical activity curriculum for child care settings. Preventing Chronic Disease Public Health Research, Practice, and Policy. 3(2), 1-7.

Eliakim, A., Nemet, D., Balakirski, Y., \& Epstein, Y. (2007) The effects of nutritional-physical activity school-based intervention on fatness and fitness in preschool children. Journal of Pediatric Endocrinology \& Metabolism. 20(6), 711-718.

Freedman, M. R., \& Alvarez, K. P. (2010). Early childhood feeding: Assessing knowledge, attitude, and practices of multi-ethnic child-care providers. The American Dietetic Association. 110(3), 447-451.

Gee, S., Rogers, V., Liu, L., \& McGarth, J. (2008). Expert committee recommendations on the assessment, prevention and treatment of child and adolescent overweight and obesity 2007-an implementation guide from the childhood obesity action network-. Retrieved 3/31, 2010, from http://www.nichq.org/documents/coan-papers-andpublications/COANImplementationGuide62607FINAL.pdf

Iruka I, \& Carver P. (2006). Initial results from the 2005 NHES Early Childhood Program Participation Survey (NCES 2006-075). Washington, DC: U.S. Department of Education. National Center for Education Statistics. 
Katzmarzyk, P. T., Srinivasan, S. R., Chen, W., Malina R. M., Bouchard, C., \& Berenson, G. S. (2004).Body mass index, waist circumference, and clustering of cardiovascular disease risk factors in a biracial sample of children and adolescents. Pediatrics, 114; 198-205.

Kraak, V. I., \& Story, M. (2010). A public health perspective on healthy lifestyles and publicprivate partnerships for global childhood obesity prevention. Journal of the American Dietetic Association 110(2), 192-200.

Levin, S., \& Martin, M. B. (2002). Catch the catawba spark: Physical activity for head start youths. Journal of Physical Education, Recreation and Dance, 73(3), 39-42.

Maher, E. J., Li, G., Carter, L., \& Johnson, d. B. (2008). Preschool child care participation and obesity at the start of kindergarten. Pediatrics. 122(2), 322-329.

Ogden, C. L., Carroll, M. D., Curtin, L. R., Lamb, M. M., \& flegal, K. M. (2010). Prevalence of high body mass index in US children and adolescents, 2007 - 2008. Journal of the American Medical Associatio. 303(3), 242-249.

Procopio, J. (2008). Using the stages of change in a public-health setting. Weight Management a Dietetic Practice Group of the American Dietetic Association, 5(3), 17-18.

Prosper, M. H., Moczulski, V. L., Qureshi, A., Weiss, M., \& Bryars, T (2009). Healthy for life/pe4me: Assessing an intervention targeting childhood obesity. Californian Journal of Health Promotion. 7(Special Issue (Obesity Prevention)), November 16, 2009.

San Diego State University. (2007) Physical education matters. Funded by The California Endowment. Los Angeles, CA, January. www.calendow.org

Spahn, J. M. (2009). The evidence for use of theory-based strategies in nutrition counseling. Weight Management a Dietetic Practice Group of the American Dietetic Association, 7(1), 14-17.

Stroup, D. F., Johnson, V. R., Proctor, D. C. \& Han, R. A. (2009) Reversing the trend of childhood obesity. Preventing Chronic Disease Public Health Research, Practice and Policy. 6(3), 1-5.

U.S. Department of Agriculture and U.S. Department of Health and Human Services.(2010). Dietary Guidelines for Americans, 2010. $7^{\text {th }}$ Edition, Washington, DC: U.S. Government Printing Office, December 2010.

U.S. Department of Health and Human Services.(2010). The surgeon general's vision for a healthy and fit nation. Office of the Surgeon General. Rockville, MD: U.S. Department of Health and Human Services.

Wang, Y.C., Orleans, T., \& Gortmaker, S. L.(2012). Reaching the healthy people goals for reducing childhood obesity. American Journal of Preventive Medicine. 42(5):437-444.

Whitaker, R. C., Gooze, R. A., Hughes, C. C., \& Findkelstein, D. M. (2009).A national survey of obesity prevention practices in head start. Archives of Pediatric Adolescent Medicine. 163(12), 1144-1150.

Wilson, T. A., Adolph, A. L., \& Butte, N. F. (2009) Nutrient adequacy and diet quality in nonoverweight and overweight Hispanic children of low socioeconomic status: The viva la familia study. The American Dietetic Association. 109(6), 1012-1021.

Author Information

*Tracy Bryars, MPH, RD, CDE, CLE

St. Jude Medical Center/St Joseph Health System

130 W. Bastanchury Road

Fullerton, CA 92835 
Bryars, T., Mouttapa, M., McMahan, S., \& Tanjasiri, S. T. / Californian Journal of Health Promotion 2012, Volume 10, Issue 1, $92-$

714-315-3581

Email: Tracy.Bryars@stjoe.org

Michele Mouttapa, PhD

California State University, Fullerton

Shari McMahan, $\mathrm{PhD}$, CHES

California State University, Fullerton

Sora Park Tanjasiri, DrPH, MPH

California State University, Fullerton

* corresponding author 
Bryars, T., Mouttapa, M., McMahan, S., \& Tanjasiri, S. T. / Californian Journal of Health Promotion 2012, Volume 10, Issue 1, $92-$ 105

\section{Appendix A}

\section{PLEASE COMPLETE THE FOLLOWING FOR YOUR CHILD}

1 How many hours per day does your child participate in "Screen Time" (TV, video games, or computer, etc.)?

2 How many days per week does your child eat fast food/at restaurants?

3 How many days per week does your child eat breakfast?

4. How many days per week does your child participate for 60 minutes or more in physical activity (walking, biking, running, sports)?

5. How many days per week does your child eat 5 or more fruits and/or vegetables in a day?

6. How many days per week does your child eat junk food (cookies, candy, soda, Cheetos ${ }^{\circledR}$, Doritos ${ }^{\circledR}$, etc.)?

7. How many days per week does your child drink 2-3 8 oz. cups of milk in a day?

8. How many days per week does your child eat healthy snacks?

Please indicate $\underline{\mathbf{O N E}}$ type of milk that your child drinks most often:

10 Does your child typically eat healthy snacks while watching TV, playing video games or on the computer?

\begin{tabular}{|c|c|c|}
\hline $\begin{array}{c}\text { Less than } \\
2 \mathrm{hrs} \\
\mathrm{O}^{1}\end{array}$ & $\begin{array}{c}2 \text { hours } \\
\bigcirc^{2}\end{array}$ & $\begin{array}{c}\text { More than } \\
2 \mathrm{hrs} \\
\mathrm{O}^{3}\end{array}$ \\
\hline 0-2 Days & 3-5 Days & 6+ Days \\
\hline $\mathrm{O}^{1}$ & $\mathrm{O}^{2}$ & $\mathrm{O}^{3}$ \\
\hline $\mathrm{O}^{1}$ & $\mathrm{O}^{2}$ & $\mathrm{O}^{3}$ \\
\hline $\mathrm{O}^{1}$ & $\mathrm{O}^{2}$ & $\mathrm{O}^{3}$ \\
\hline $\mathrm{O}^{1}$ & $\mathrm{O}^{2}$ & $\mathrm{O}^{3}$ \\
\hline $\mathrm{O}^{1}$ & $\mathrm{O}^{2}$ & $\mathrm{O}^{3}$ \\
\hline $\mathrm{O}^{1}$ & $\mathrm{O}^{2}$ & $\mathrm{O}^{3}$ \\
\hline $\mathrm{O}^{1}$ & $\mathrm{O}^{2}$ & $\mathrm{O}^{3}$ \\
\hline \multicolumn{2}{|c|}{$\begin{array}{l}\mathrm{O}^{2} 2 \% \text { low fat } \\
\mathrm{O}^{5} \text { Soymilk }\end{array}$} & $\begin{array}{l}\mathrm{O}^{3} \text { Nonfat } \\
\mathrm{O}^{6} \text { None }\end{array}$ \\
\hline \multicolumn{2}{|c|}{$\mathrm{O}^{2}$ Sometimes } & $\mathrm{O}^{3}$ Never \\
\hline
\end{tabular}




\section{Appendix B}

\section{Picture Scales for Preschool Children Structured Interview (Script)}

Instructions and Test Procedure

At the beginning of the knowledge test, each child is asked if they know what "healthy" means. They are then provided with an age-appropriate explanation, such as, "Being healthy means that you can play outside, you don't get sick, and you feel good. Can you tell me some things that you might do to stay healthy?" The child is then asked to point to the food/activity that will help you stay healthy and grow big and strong.

\section{Questions asked by Assessment Team Member:}

Can you tell me which food is healthier? Tuna Sandwich or Hot Dog

Please point to the healthier food item picture.

This question is asked for the following food choices:

Orange Juice or Coke

Potato Chips or Strawberry Yogurt

Fruit Loops or Cheerios

Raisins or Chocolate (Hershey's) Bar

Peanuts or French Fries

Can you tell me which activity is healthier? Walking or Running

Please point to the healthier activity.

This question is asked for the following activity choices:

Pulling the wagon or sitting in the wagon

Pushing the truck or riding a tricycle

Kicking a ball or rolling a ball

Dancing with radio or playing legos

Climbing on Monkey Bars or Going down a

slide

When the child is done the Assessment Team Member thanks the student 